\title{
Long-term efficacy and safety of infliximab and cyclosporine combination therapy for refractory uveoretinitis in Behçet's disease
}

This article was published in the following Dove Medical Press journal:

Clinical Ophthalmology

\author{
Atsuko Katsuyama' \\ Sentaro Kusuhara' \\ Ryuto Nishisho' \\ Wataru Matsumiya' \\ Atsushi Azumi² \\ Makoto Nakamura' \\ 'Department of Surgery, Division \\ of Ophthalmology, Kobe University \\ Graduate School of Medicine, \\ Chuo-ku, Kobe 650-00I7, Japan; \\ 2Department of Ophthalmology, \\ Kobe Kaisei Hospital, Nada-ku, \\ Kobe 657-0068, Japan
}

Purpose: This study aimed to evaluate the long-term efficacy and safety of infliximab (IFX) and cyclosporine (CsA) combination therapy for refractory uveoretinitis in Behçet's disease (BD). Patients and methods: The study involved a retrospective review of the medical records of 11 patients with Behçet's uveoretinitis refractory to conventional treatment who had been treated with IFX+CsA combination therapy. The frequency of ocular inflammatory attacks and a Behçet's disease ocular attack score 24 (BOS24) were used as indices for the evaluation of efficacy during each 6-month period prior to and following initiation of therapy. For the assessment of safety, adverse events (AEs) were recorded throughout the treatment period.

Results: The patients had received IFX+CsA combination therapy for $5.6 \pm 2.3$ years. The frequency of ocular attacks per 6-month period decreased markedly from $2.9 \pm 1.6$ during the baseline period to $0.6 \pm 0.9$ during months $1-6,0.5 \pm 0.9$ during months $7-12,0.3 \pm 0.5$ during months $13-18,0.3 \pm 0.7$ during months $19-24$, and $0.0 \pm 0.0$ thereafter $(P=0.003)$. The BOS 24 score per ocular attack significantly decreased from 5.2 \pm 2.4 during the baseline period to $1.5 \pm 2.1$ during months $1-6,1.7 \pm 3.1$ during months $7-12$, $1.6 \pm 2.9$ during months $13-18$, and $0.4 \pm 1.0$ during months 19-24 ( $P=0.002)$. No serious AEs were observed, with the exception of urinary tract infection and cataract progression. Two patients exhibited transient elevation of the serum creatinine level, which was normalized following a reduction in the dose of CsA.

Conclusion: For refractory Behçet's uveoretinitis, IFX+CsA combination therapy offers a promising treatment option as it appears to have an acceptable safety profile and can reduce the frequency and severity of ocular inflammatory attacks over a long period of time.

Keywords: Behçet's disease, uveitis, infliximab, cyclosporine, efficacy, safety

\section{Introduction}

Behçet's disease (BD) is a rare chronic systemic inflammatory disorder of the blood vessels and tissues, which is characterized by relapsing and remitting episodes of oral aphthous ulcers, genital ulcers, skin lesions, and uveoretinitis. ${ }^{1,2}$ Uveoretinitis in BD manifests as anterior uveitis, posterior uveitis, or panuveitis and is composed of a chronic or long-lasting background inflammation and episodic acute inflammation (ocular attack). As the ocular tissue is irreversibly damaged by repeated ocular attacks, $\mathrm{BD}$ has long been a principal cause of blindness as a result of certain patients being refractory to conventional immunosuppressive therapy. 3,4

Tumor necrosis factor-alpha $(\mathrm{TNF} \alpha)$ is a proinflammatory cytokine and the increased production of TNF $\alpha$ is known to be associated with higher activity of ocular symptoms in patients with BD. ${ }^{5}$ The advent of the use of infliximab (IFX), a chimeric monoclonal antibody against $\mathrm{TNF} \alpha$, has had a substantial impact on the clinical course
Correspondence: Sentaro Kusuhara Ophthalmology, Kobe University Graduate School of Medicine,

7-5-2 Kusunoki-cho, Chuo-ku,

Kobe 650-0017, Japan

Tel +8 I78 3826048

$\mathrm{Fax}+81783826059$

Email kusu@med.kobe-u.ac.jp
Clinical Ophthalmology 2019:13 521-527

(c) (i) () 2019 Katsuyama et al. This work is published and licensed by Dove Medical Press Limited. The full terms of this license are available at https://www.dovepress.com/terms.ph (c) $\mathrm{BY}$ and incorporate the Creative Commons Attribution - Non Commercial (unported, v3.0) License (http://creativecommons.org/licenses/by-n/ 3.00$)$. By accessing the work you hereby accept the Terms. Non-commercial uses of the work are permitted without any further permission from Dove Medical Press Limited, provided the work is properly attributed. For permission for commercial use of this work, please see paragraphs 4.2 and 5 of our Terms (https://www.dovepress.com/terms.php). 
of Behçet's uveoretinitis and has markedly improved visual outcomes, as it can reduce the frequency of ocular attacks and preserve vision in eyes otherwise resistant to standard immunosuppressive therapy. ${ }^{6-8}$ Upon the integration of IFX therapy into the treatment paradigm of BD-related uveitis, the primary concern of uveitis specialists has been the shortterm efficacy of IFX therapy on recalcitrant ocular inflammation. However, multiple lines of evidence have supported the beneficial effects of IFX in the treatment of Behçet's uveoretinitis, which has increased interest in its long-term efficacy and safety. ${ }^{9}$

IFX contains $\sim 25 \%$ mouse-derived amino acids and thus is considered to produce an immune response to itself, termed immunogenicity. For a situation in which TNF $\alpha$ inhibitors, including IFX, are recognized by the immune system as a foreign protein, anti-drug antibodies (ADAs) can be generated and cause unfavorable effects on the clinical course, including the loss of response and infusion reactions. ${ }^{10-12}$ Accordingly, the concomitant use of immunomodulatory agents with TNF $\alpha$ inhibitors is recommended to reduce ADA formation in the management of rheumatoid arthritis, spondyloarthritis, psoriasis, and inflammatory bowel diseases. ${ }^{11}$ However, to date, there is little evidence in the English literature on the impact of combination therapy using IFX and immunomodulatory agents on the long-term clinical course of BD-associated uveoretinitis. ${ }^{13}$ Therefore, the present study aimed to evaluate the efficacy and safety of combined therapy with IFX and cyclosporine (CsA) (IFX+CsA) in patients with $\mathrm{BD}$ with refractory uveoretinitis.

\section{Materials and methods}

\section{Study design and inclusion/exclusion criteria}

In this retrospective study, the medical records of patients who had been diagnosed with Behçet's uveoretinitis were reviewed. The diagnostic criteria used were as defined by the BD Research Committee of Japan for the diagnosis of BD. ${ }^{14}$ Data extracted from the medical records of patients included age, gender, best-corrected visual acuity (BCVA), intraocular inflammation according to the National Eye Institute criteria adapted by the Standardisation of Uveitis Nomenclature Working Group, ${ }^{15,16}$ systemic medications, and adverse events (AEs). The inclusion criteria were as follows: patients had uncontrolled relapse of ocular inflammation following conventional immunosuppressive treatment, a follow-up period of $>6$ months preceding the initiation of IFX + CsA combination therapy, and initiation of IFX + CsA combination therapy between January 2006 and March 2010.
The exclusion criteria were as follows: the presence of inflammatory ocular diseases other than Behçet's uveoretinitis, systemic inflammatory conditions other than BD, and a history of anti-TNF $\alpha$ therapy. This study was approved by the Institutional Review Board of Kobe University Graduate School of Medicine and adhered to the tenets of the Declaration of Helsinki. The Institutional Review Board exempted us from obtaining patients' consent as this retrospective chart review used de-identified data.

\section{Treatment and outcome variables}

IFX was administered intravenously at a dose of $5 \mathrm{mg} / \mathrm{kg}$ in weeks 0,2 , and 6 as induction therapy and then every 8 weeks. CsA was dosed concomitantly with IFX according to a gradual dose adjustment scheme. The dose of CsA and local corticosteroids used for ocular inflammation was left to the discretion of the attending ophthalmologists. Prior to IFX+CsA therapy, rheumatologists performed systemic evaluation, which included taking a history of allergies, a tuberculin skin test with purified protein derivative (or interferon-gamma release assay), electrocardiography, chest computed tomography, viral infection, and cancer. The efficacy of IFX+CsA therapy was assessed by the frequency and severity of ocular inflammatory attack. Ocular inflammatory attack was defined as an acute or sudden-onset worsening ocular inflammation, and the frequency of ocular inflammatory attack per 6-month period was used as the primary outcome measure. As an ocular attack may occur only in one eye, simultaneous bilateral ocular attacks were counted as two ocular attacks. The severity of each ocular inflammatory attack was quantified using the Behçet's disease ocular attack score 24 (BOS24) scoring system, which is a scoring system developed by Kaburaki et a $1{ }^{17}$ based on intraocular inflammatory findings, with 24 being the highest worst score. Safety was assessed using the information provided by attending ophthalmologists and rheumatologists who documented serious AEs and any AEs possibly related to the therapy. The BOS24 score per ocular attack, BCVA, and AEs were designated as secondary outcome measures in the study.

\section{Statistical analyses}

The frequency of ocular attacks was evaluated on a per patient basis. Numerical data are provided as the mean \pm standard deviation unless otherwise specified, and missing data were imputed using the last observation carried forward method. Decimal BCVAs determined using the Landolt $\mathrm{C}$ chart were converted to a logarithm of the minimum angle of resolution (logMAR) BCVAs, as reported previously. ${ }^{18}$ 
For convenience, light perception and no light perception were regarded as a logMAR BCVA of 4.00 and 5.00, respectively, in this study. Statistical analyses were performed using SPSS software version 24.0 (IBM Corporation, Armonk, NY, USA). Linear mixed models analysis was used to assess the change of variables over time. $P<0.05$ (two-sided) was accepted as statistically significant in each analysis.

\section{Results}

Of the 14 consecutive BD patients who received IFX + CsA combination therapy for refractory uveoretinitis at Kobe University Hospital, treatment for three of the patients had commenced at another hospital. Therefore, the remaining 11 patients met the criteria of the study. The patients' characteristics at baseline, at the start of IFX+CsA therapy, are presented in Table 1 . The patients had received IFX+CsA combination therapy for $>3$ years (ranging between 3 and 9 years), with the exception of one patient who was lost to follow-up due to moving out of the area at 1 year, and the mean duration of IFX + CsA combination therapy was 5.6 \pm 2.3 years. The induction dose of CsA was $152.3 \pm 56.4 \mathrm{mg} /$ day $(2.52 \pm 1.03 \mathrm{mg} / \mathrm{kg} /$ day $)$, and the dose was reduced in the maintenance phase to $113.6 \pm 51.7 \mathrm{mg} /$ day $(1.88 \pm 0.95 \mathrm{mg} / \mathrm{kg} / \mathrm{day})$ at month 12 and to $88.6 \pm 32.3 \mathrm{mg} /$ day $(1.44 \pm 0.54 \mathrm{mg} / \mathrm{kg} /$ day) at month 24 .

Figure 1 shows the change of frequency over time following commencement of IFX+CsA combination therapy.

Table I Patients' characteristics at baseline

\begin{tabular}{|c|c|}
\hline Number of patients & II \\
\hline Age (years)* & $45.1 \pm 8.6$ \\
\hline Gender, male (\%)/female (\%) & $8(73) / 3(27)$ \\
\hline \multicolumn{2}{|l|}{$\log M A R$ BCVA* } \\
\hline Right eye & $1.15 \pm 1.58$ \\
\hline Left eye & $0.90 \pm 1.48$ \\
\hline Number of ocular inflammatory attacks during the last & $2.9 \pm 1.6$ \\
\hline 6 months* & \\
\hline BOS24 score/ocular attack during the last 6 months* & $5.2 \pm 2.4$ \\
\hline \multicolumn{2}{|l|}{ Previous systemic treatment, n (\%) } \\
\hline $\mathrm{CsA}+\mathrm{Col}$ & $4(36)$ \\
\hline $\mathrm{CsA}+\mathrm{CS}$ & $2(18)$ \\
\hline CsA & I (9) \\
\hline CsA+NSAID & I (9) \\
\hline CsA+Col+NSAID & I (9) \\
\hline $\mathrm{CsA}+\mathrm{Col}+\mathrm{CS}$ & I (9) \\
\hline CsA+Col+adalimumab** & I (9) \\
\hline
\end{tabular}

Notes: *Data are presented as the mean \pm standard deviation. **Adalimumab was used for the treatment of extraocular symptoms, and adalimumab was discontinued following the initiation of IFX + CsA combination therapy.

Abbreviations: $\log M A R$, logarithm of the minimum angle of resolution; BCVA, best-corrected visual acuity; BOS24, Behçet's disease ocular attack score 24; CsA, cyclosporine; Col, colchicine; CS, corticosteroid; NSAID, non-steroidal antiinflammatory drug; IFX, infliximab.
The frequency of ocular attacks per 6 months decreased considerably from $2.9 \pm 1.6$ during the baseline period to $0.6 \pm 0.9$ during months $1-6$ and then tapered to $0.5 \pm 0.9$ during months $7-12,0.3 \pm 0.5$ during months $13-18,0.3 \pm 0.7$ during months $19-24$, and $0.0 \pm 0.0$ thereafter $(P=0.003)$. The BOS24 score per ocular attack decreased significantly from 5.2 \pm 2.4 during the baseline period to $1.5 \pm 2.1$ during months $1-6$, $1.7 \pm 3.1$ during months $7-12,1.6 \pm 2.9$ during months $13-18$, and $0.4 \pm 1.0$ during months $19-24(P=0.002)$ (Figure 2$)$. The $\log$ MAR BCVA in the right eye was $1.15 \pm 1.58$ at baseline, $1.19 \pm 1.79$ at 12 months, and $1.13 \pm 1.77$ at 24 months $(P=0.047)$. The logMAR BCVA in the left eye was $0.90 \pm 1.48$ at baseline, $0.77 \pm 1.50$ at 12 months, and $0.85 \pm 1.65$ at 24 months $(P=0.097)$. Following a 2-year treatment period with IFX+CsA, the $\log$ MAR BCVA remained unchanged or improved in $82 \%(9 / 11)$ of patients. Changes in Snellenequivalent visual acuities are presented in Table 2.

No serious AEs were documented, with the exception of urinary tract infection $(n=1)$ and significant cataract progression $(n=1)$. As a minor AE, two patients exhibited transient elevation of the serum creatinine level, which normalized following a dose reduction of CsA. No other AEs, such as infusion reaction or upper airway inflammation, were reported.

\section{Discussion}

In the present study, IFX+CsA combination therapy was well tolerated and led to significant long-term reductions in the frequency and severity of ocular inflammatory attacks in patients with refractory Behçet's uveoretinitis. No loss of response to IFX+CsA combination therapy was observed and none of the patients discontinued therapy due to AEs during the treatment period. These results are likely to improve current understanding of the management of Behçet's uveoretinitis.

The frequency of ocular attacks per 6-month period was decreased significantly by IFX+CsA combination therapy from 2.9 during the baseline period to 0.0 at 24 months in the study. As reported previously, IFX therapy with or without immunomodulatory agents is efficacious in managing refractory uveoretinitis in patients with BD. ${ }^{6,7,9,19-24}$ Ohno et $\mathrm{al}^{6}$ conducted a prospective study and reported the short-term efficacy of IFX $(5 \mathrm{mg} / \mathrm{kg})$ monotherapy in seven patients with BD with refractory uveoretinitis. Following treatment, the mean number of ocular attacks per 14-week period decreased from 3.79 to 0.98 . Another prospective study of 13 patients with BD by Tugal-Tutkun et al $^{19}$ demonstrated that IFX therapy combined with corticosteroids and/or azathioprine 


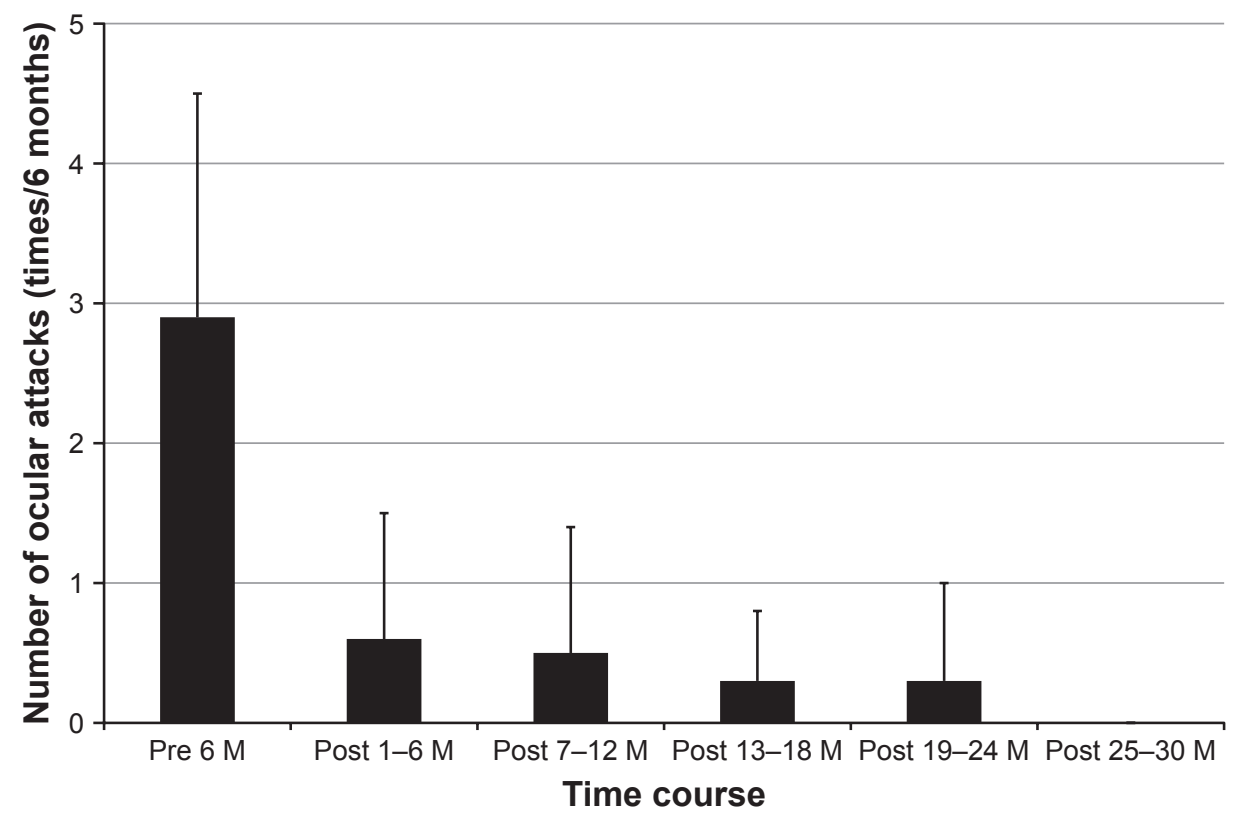

Figure I Effect of IFX+CsA combination therapy on the frequency of ocular inflammatory attacks. The frequency of ocular inflammatory attacks, assessed by the mean number of ocular attacks per 6-month period, decreases significantly following the initiation of IFX $+C s A$ combination therapy ( $P=0.003$, linear mixed models analysis). Data are presented as the mean \pm standard deviation.

Abbreviations: IFX, infliximab; CsA, cyclosporine; M, months.

significantly reduced the frequency of ocular attacks per 22-week period from 2.4 to 1.0. The efficacy of IFX therapy has also been appraised in large-scale studies. Okada et al ${ }^{7}$ prospectively evaluated the 1-year efficacy of IFX therapy on refractory uveoretinitis in 63 patients with $\mathrm{BD}$. The study showed an improvement of uveoretinitis in 69\% (33/48) of the patients and a decrease in the number of ocular attacks per 6-month period from 2.66 to 0.79 . Takeuchi et $\mathrm{al}^{9}$ conducted a multicenter retrospective study to evaluate the long-term efficacy of IFX for the treatment of 164 patients with Behçet's uveoretinitis and showed that the beneficial effect of IFX on the frequency of ocular attacks was maintained irrespective

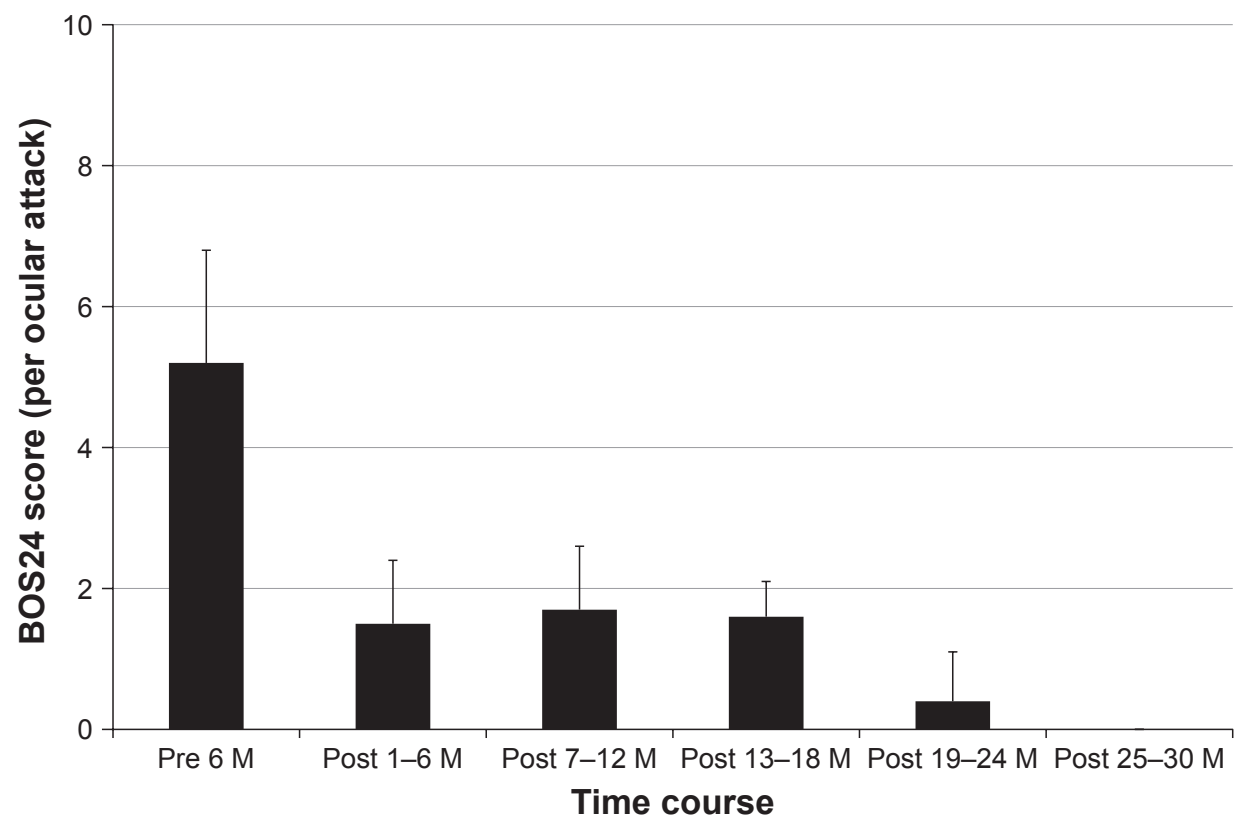

Figure 2 Effect of IFX+CsA combination therapy on the severity of ocular inflammatory attacks. IFX+CsA combination therapy significantly decreased the severity of ocular inflammatory attack as evaluated by the mean BOS24 value in each ocular attack ( $P=0.002$, linear mixed models analysis). Data are presented as the mean \pm standard deviation. Abbreviations: IFX, infliximab; CsA, cyclosporine; BOS24, Behçet's disease ocular attack score 24; M, months. 
Table 2 Changes in Snellen-equivalent visual acuities after IFX+CsA combination therapy

\begin{tabular}{|c|c|c|c|c|c|}
\hline BCVA & Baseline & 6 months & 12 months & 18 months & 24 months \\
\hline \multicolumn{6}{|l|}{ OD } \\
\hline$<2 / 200$ & $2(18)$ & $2(18)$ & $2(18)$ & $2(18)$ & $2(18)$ \\
\hline $2 / 200$ to $<20 / 200$ & I (9) & I (9) & $2(18)$ & I (9) & I (9) \\
\hline $20 / 200$ to $<20 / 40$ & $3(27)$ & $3(27)$ & I (9) & $2(18)$ & $2(18)$ \\
\hline $20 / 40$ to $<20 / 20$ & $3(27)$ & I (9) & $2(18)$ & $2(18)$ & $3(27)$ \\
\hline$\geq 20 / 20$ & $2(18)$ & $4(36)$ & $4(36)$ & $4(36)$ & $3(27)$ \\
\hline \multicolumn{6}{|l|}{ OS } \\
\hline$<2 / 200$ & I (9) & I (9) & I (9) & $2(18)$ & $2(18)$ \\
\hline $2 / 200$ to $<20 / 200$ & $2(18)$ & I (9) & I (9) & I (9) & $0(0)$ \\
\hline $20 / 200$ to $<20 / 40$ & $2(18)$ & $3(27)$ & $2(18)$ & $2(18)$ & $2(18)$ \\
\hline $20 / 40$ to $<20 / 20$ & $4(36)$ & $2(18)$ & $3(27)$ & $2(18)$ & $2(18)$ \\
\hline$\geq 20 / 20$ & $2(18)$ & $4(36)$ & $4(36)$ & $4(36)$ & $5(45)$ \\
\hline
\end{tabular}

Note: Data are provided as the number of eyes (percentage).

Abbreviations: IFX, infliximab; CsA, cyclosporine; BCVA, best-corrected visual acuity (Snellen-equivalent); OD, right eye; OS, left eye.

of the duration of IFX treatment. However, these two largescale studies contained subjects who underwent combination therapy with IFX and immunomodulatory agents which included CsA; therefore, the true effect of IFX on Behçet's uveoretinitis in a large cohort remains to be fully elucidated. A 1-year follow-up study of 124 patients with BD aiming to assess the efficacy of anti-TNF $\alpha$ therapy in refractory uveitis by Calvo-Rio et $a l^{8}$ has the same problem, although the study showed overall efficacy of anti-TNF $\alpha$ therapy. We integrated these data and normalized them using a back-ofthe-envelope calculation in order to compare them with data from the present study. The mean frequency of ocular attacks in the previous studies was comparable to that of the present study prior to treatment ( 3.0 vs 2.9 ), whereas the frequency was lower in the present study than in the previous studies ( 0.8 vs 0.0$)$ following treatment. The reason for the superior efficacy in the outcome of the present study may be due to the following: 1) concomitant $\mathrm{CsA}$ use reduced $\mathrm{ADA}$ formation and prevented secondary non-response; 2) CsA acted as an additional immunosuppressant to IFX; or 3) both.

Another index used in the evaluation of the efficacy of IFX+CsA combination therapy in the present study was the BOS24 score per ocular attack. ${ }^{17}$ The mean BOS24 score per ocular attack was reduced immediately following IFX + CsA combination therapy and gradually decreased over 24 months, which indicates that IFX+CsA combination therapy was also effective in reducing the magnitude of ocular inflammatory attack in Behçet's uveoretinitis. In the clinical practice of systemic inflammatory disease, an established scoring system is utilized for the assessment of disease activity, such as the Disease Activity Score of 28 for rheumatoid arthritis and the Ankylosing Spondylitis Disease Activity Score for axial spondyloarthritis. ${ }^{25,26}$ For BD, the Behçet's Disease Current Activity Form (BDCAF) has been used for this purpose; however, the BDCAF is a question-based subjective scoring system for clinical manifestations, including fatigue, headache, and oral aphthous ulcers. ${ }^{27,28}$ By contrast, the BOS24 scoring system has an advantage in that it can provide detailed objective information on the activity of ocular inflammation. The usefulness of the BOS24 scoring system was validated in a previous retrospective study. Tanaka et al ${ }^{29}$ analyzed 50 patients with ocular BD and found that the total BOS24 score over a 5-year period was an independent factor for BCVA deterioration. Kaburaki et $\mathrm{al}^{17}$ reported that the mean BOS24 score in each ocular attack decreased from 5.8 during the baseline period to 4.0 during the 19-24 months following IFX therapy. As the mean BOS24 score per ocular attack during the same time period was 5.2 and 0.4 , respectively, in the present study, IFX+CsA combination therapy may also be more effective in reducing the magnitude of ocular inflammation in BD.

In theory, the additional use of CsA with IFX can attenuate the formation of anti-IFX antibodies and thereby exerts a prophylactic effect on IFX-induced AEs. As expected, the overall incidence of AEs was lower in the present study compared with that of previous studies. The incidence of AEs in the present study was $36 \%(4 / 11)$, and $50 \%$ of these were serious cases as both patients were hospitalized for treatment (cataract surgery is usually performed in an inpatient setting at Kobe University Hospital). This figure is similar to that reported in the previous studies: a score of $35 \%$ was reported in the retrospective analysis of 164 patients, ${ }^{9}$ while $46 \%$ was 
reported in the prospective analysis of 63 patients. ${ }^{7}$ Infusion reaction is one of the most common IFX-related AEs, and the frequency was reported to be $12.3 \%$ in a real-world practice of 1,632 patients with rheumatic conditions. ${ }^{30}$ In the present study, no infusion reaction was observed over the mean duration of 5.6 years. This is likely to be attributed to the concomitant use of CsA; however, the effect of CsA on ADA formation in the present study is unknown, as serum anti-IFX antibody levels were not measured. To maintain both the efficacy and safety, lower daily CsA doses were selected for combination with IFX: the mean CsA dose was $113.6 \mathrm{mg} /$ day $(1.88 \mathrm{mg} / \mathrm{kg} /$ day $)$ at 12 months and $88.6 \mathrm{mg} /$ day $(1.44 \mathrm{mg} / \mathrm{kg} /$ day $)$ at 24 months, which may have led to the absence of CsA-related AEs in the study.

There were a number of limitations in the present study. First, CsA was coadministered with IFX despite there being insufficient evidence supporting the beneficial effects of CsA on disease management compared with methotrexate in rheumatic conditions. ${ }^{11}$ This was due to restrictions in the health care system in Japan. The current public Japanese medical insurance system only covers CsA for the treatment of Behçet's uveoretinitis. Second, as discussed earlier, the levels of serum TNFo, IFX, and anti-IFX antibodies were not measured by the current Japanese medical insurance system for the same reason. The detection of ADAs is not standardized due to the lack of an ideal assay to measure serum levels of the drug itself, free ADAs, and the drug-ADA complex. ${ }^{31}$ In addition, binding assays, including ELISA, do not provide information concerning the function of ADAs or the drug-ADA complex. ${ }^{32}$ Consequently, the mechanism by which the combined use of IFX and CsA contributed to good clinical courses in the present study remains to be elucidated. Finally, the small sample size and retrospective nature of this study are likely to affect the results. For instance, the frequency of AEs may be underestimated as the clinical data were not collected in a designated manner and the small sample size precluded the evaluation of low-frequency AEs.

\section{Conclusion}

IFX + CsA combination therapy may offer a promising treatment option for refractory Behçet's uveoretinitis as it can decrease the frequency and severity of ocular inflammatory attacks with acceptable safety on a long-term basis. We hope that a future large-scale prospective cohort study would be conducted to confirm the efficacy and safety of IFX+CsA combination therapy for refractory uveoretinitis in BD.

\section{Disclosure}

The authors report no conflicts of interest in this work.

\section{References}

1. Sakane T, Takeno M, Suzuki N, Inaba G. Behcet's disease. $N$ Engl $J$ Med. 1999;341(17):1284-1291. doi:10.1056/NEJM199910213411707

2. Kitaichi N, Miyazaki A, Iwata D, Ohno S, Stanford MR, Chams H. Ocular features of Behcet's disease: an international collaborative study. $\mathrm{Br} J$ Ophthalmol. 2007;91(12):1579-1582. doi:10.1136/bjo.2007.123554

3. Tugal-Tutkun I, Onal S, Altan-Yaycioglu R, Huseyin Altunbas H, Urgancioglu M. Uveitis in Behcet disease: an analysis of 880 patients. Am J Ophthalmol. 2004;138(3):373-380. doi:10.1016/j.ajo.2004.03.022

4. Kacmaz RO, Kempen JH, Newcomb C, et al. Ocular inflammation in Behcet disease: incidence of ocular complications and of loss of visual acuity. Am J Ophthalmol. 2008;146(6):828-836. doi:10.1016/j. ajo.2008.06.019

5. Nakamura S, Sugita M, Tanaka S, Ohno S. Enhanced production of in vitro tumor necrosis factor-alpha from monocytes in Behcet's disease. Nippon Ganka Gakkai Zasshi. 1992;96(10):1282-1285.

6. Ohno S, Nakamura S, Hori S, et al. Efficacy, safety, and pharmacokinetics of multiple administration of infliximab in Behcet's disease with refractory uveoretinitis. J Rheumatol. 2004;31(7):1362-1368.

7. Okada AA, Goto H, Ohno S, Mochizuki M. Ocular Behcet's Disease Research Group Of Japan. Multicenter study of infliximab for refractory uveoretinitis in Behcet disease. Arch Ophthalmol. 2012;130(5): 592-598. doi:10.1001/archophthalmol.2011.2698

8. Calvo-Rio V, Blanco R, Beltran E, et al. Anti-TNF-alpha therapy in patients with refractory uveitis due to Behcet's disease: a 1-year follow-up study of 124 patients. Rheumatology (Oxford). 2014;53(12): 2223-2231. doi:10.1093/rheumatology/keu266

9. Takeuchi M, Kezuka T, Sugita S, etal. Evaluation of the long-term efficacy and safety of infliximab treatment for uveitis in Behcet's disease: a multicenter study. Ophthalmology. 2014;121(10):1877-1884. doi:10.1016/ j.ophtha.2014.04.042

10. Iwata D, Namba K, Mizuuchi K, et al. Correlation between elevation of serum antinuclear antibody titer and decreased therapeutic efficacy in the treatment of Behcet's disease with infliximab. Graefes Arch Clin Exp Ophthalmol. 2012;250(7):1081-1087. doi:10.1007/s00417-011-1908-1

11. Jani M, Barton A, Warren RB, Griffiths CE, Chinoy H. The role of DMARDs in reducing the immunogenicity of TNF inhibitors in chronic inflammatory diseases. Rheumatology (Oxford). 2014;53(2):213-222. doi:10.1093/rheumatology/ket260

12. Pecoraro V, De Santis E, Melegari A, Trenti T. The impact of immunogenicity of TNFalpha inhibitors in autoimmune inflammatory disease. A systematic review and meta-analysis. Autoimmun Rev. 2017;16(6): 564-575. doi:10.1016/j.autrev.2017.04.002

13. Urruticoechea-Arana A, Cobo-Ibanez T, Villaverde-Garcia V, et al. Efficacy and safety of biological therapy compared to synthetic immunomodulatory drugs or placebo in the treatment of Behcet's disease associated uveitis: a systematic review. Rheumatol Int. 2019;39(1):47-58.

14. Mizushima Y. Revised diagnostic criteria for Behcet's disease in 1987. Ryumachi. 1988;28(1):66-70.

15. Nussenblatt RB, Palestine AG, Chan CC, Roberge F. Standardization of vitreal inflammatory activity in intermediate and posterior uveitis. Ophthalmology. 1985;92(4):467-471.

16. Jabs DA, Nussenblatt RB, Rosenbaum JT; Standardization of Uveitis Nomenclature Working Group. Standardization of uveitis nomenclature for reporting clinical data. Results of the First International Workshop. Am J Ophthalmol. 2005;140(3):509-516.

17. Kaburaki T, Namba K, Sonoda KH, et al. Behcet's disease ocular attack score 24: evaluation of ocular disease activity before and after initiation of infliximab. Jpn JOphthalmol.2014;58(2):120-130. doi:10.1007/s10384013-0294-0

18. Holladay JT. Visual acuity measurements. $J$ Cataract Refract Surg. 2004;30(2):287-290. doi:10.1016/j.jcrs.2004.01.014

19. Tugal-Tutkun I, Mudun A, Urgancioglu M, et al. Efficacy of infliximab in the treatment of uveitis that is resistant to treatment with the combination of azathioprine, cyclosporine, and corticosteroids in Behcet's disease: an open-label trial. Arthritis Rheum. 2005;52(8):2478-2484. doi:10.1002/art.2123 
20. Abu El-Asrar AM, Abboud EB, Aldibhi H, Al-Arfaj A. Long-term safety and efficacy of infliximab therapy in refractory uveitis due to Behcet's disease. Int Ophthalmol. 2005;26(3):83-92. doi:10.1007/ s10792-006-9006-9

21. Accorinti M, Pirraglia MP, Paroli MP, Priori R, Conti F, Pivetti-Pezzi P. Infliximab treatment for ocular and extraocular manifestations of Behcet's disease. Jpn J Ophthalmol. 2007;51(3):191-196. doi:10.1007/s10384006-0425-y

22. Niccoli L, Nannini C, Benucci M, et al. Long-term efficacy of infliximab in refractory posterior uveitis of Behcet's disease: a 24-month follow-up study. Rheumatology (Oxford). 2007;46(7):1161-1164. doi:10.1093/ rheumatology/kem 101

23. Capella MJ, Foster CS. Long-term efficacy and safety of infliximab in the treatment of Behcet's disease. Ocul Immunol Inflamm. 2012;20(3): 198-202. doi:10.3109/09273948.2012.670360

24. Al Rashidi S, Al Fawaz A, Kangave D, Abu El-Asrar AM. Longterm clinical outcomes in patients with refractory uveitis associated with Behcet disease treated with infliximab. Ocul Immunol Inflamm. 2013;21(6):468-474. doi:10.3109/09273948.2013.779727

25. Nam JL, Takase-Minegishi K, Ramiro S, et al. Efficacy of biological disease-modifying antirheumatic drugs: a systematic literature review informing the 2016 update of the EULAR recommendations for the management of rheumatoid arthritis. Ann Rheum Dis. 2017;76(6): 1113-1136. doi:10.1136/annrheumdis-2016-210713

26. Machado PM, Landewe R, Heijde DV. Assessment of SpondyloArthritis international Society. Ankylosing Spondylitis Disease Activity Score (ASDAS): 2018 update of the nomenclature for disease activity states. Ann Rheum Dis. 2018;77(10):1539-1540. doi:10.1136/annrheumdis2018-213184
27. Bhakta BB, Brennan P, James TE, Chamberlain MA, Noble BA, Silman AJ. Behcet's disease: evaluation of a new instrument to measure clinical activity. Rheumatology (Oxford). 1999;38(8):728-733.

28. Neves FS, Moraes JC, Kowalski SC, Goldenstein-Schainberg C, Lage LV, Goncalves CR. Cross-cultural adaptation of the Behcet's Disease Current Activity Form (BDCAF) to Brazilian Portuguese language. Clin Rheumatol. 2007;26(8):1263-1267. doi:10.1007/s10067006-0484-y

29. Tanaka R, Murata H, Takamoto M, et al. Behcet's disease ocular attack score 24 and visual outcome in patients with Behcet's disease. Br J Ophthalmol. 2016;100(7):990-994. doi:10.1136/bjophthalmol2015-307362

30. Choquette D, Faraawi R, Chow A, Rodrigues J, Bensen WJ, Nantel F. Incidence and management of infusion reactions to infliximab in a prospective real-world community registry. J Rheumatol. 2015;42(7): 1105-1111. doi:10.3899/jrheum. 140538

31. Schaeverbeke T, Truchetet ME, Kostine M, Barnetche T, Bannwarth B, Richez C. Immunogenicity of biologic agents in rheumatoid arthritis patients: lessons for clinical practice. Rheumatology (Oxford). 2016; 55(2):210-220. doi:10.1093/rheumatology/kev277

32. Lazar-Molnar E, Delgado JC. Immunogenicity assessment of tumor necrosis factor antagonists in the clinical laboratory. Clin Chem. 2016; 62(9):1186-1198. doi:10.1373/clinchem.2015.242875
Clinical Ophthalmology

\section{Publish your work in this journal}

Clinical Ophthalmology is an international, peer-reviewed journa covering all subspecialties within ophthalmology. Key topics include: Optometry; Visual science; Pharmacology and drug therapy in eye diseases; Basic Sciences; Primary and Secondary eye care; Patient Safety and Quality of Care Improvements. This journal is indexed on

Submit your manuscript here: http://www.dovepress.com/clinical-ophthalmology-journal

\section{Dovepress}

PubMed Central and CAS, and is the official journal of The Society of Clinical Ophthalmology (SCO). The manuscript management system is completely online and includes a very quick and fair peer-review system, which is all easy to use. Visit http://www.dovepress.com/ testimonials.php to read real quotes from published authors. 